\title{
Sacrificial Wafer Bonding for Planarization After Very Deep Etching
}

\author{
Vincent L. Spiering, J. W. Berenschot, Miko Elwenspoek, and Jan H. J. Fluitman, Member, IEEE
}

\begin{abstract}
A new technique is presented that provides planarization after a very deep etching step in silicon. This offers the possibility for as well resist spinning and layer patterning as realization of bridges or cantilevers across deep holes or grooves. The sacrificial wafer bonding technique contains a wafer bond step followed by an etch back. Results of polymer bonding followed by dry etching and anodic bonding combined with $\mathrm{KOH}$ etching are discussed. The polymer bonding has been applied in a strain based membrane pressure sensor to pattern the strain gauges and to provide electrical connections across a deep corrugation in a thin silicon nitride membrane by metal bridges. [107]
\end{abstract}

\section{INTRODUCTION}

$\mathbf{T}$ HE DESIGN of micromachined devices is often limited by the impossibility of layer patterning by resist spinning on a wafer surface containing large steps in height. The standard resist spinning method needs a flat surface for a coverage with a uniform layer thickness. This means that after etching deep grooves or holes in a wafer, it is difficult to pattern existing or new deposited layers. Usually it is tried to carry out the deposition and patterning of all layers first and finish the process with the deep etch step. This, however, is not always possible because technology- and material-based constraints play a role in the possibilities of chronology of the process steps. If for example a deep etched groove is used as a mould to shape a structure, the cronology can not be reversed: the deep etch step has to be followed by the deposition of the structure material.

Alternative methods to apply photoresist are dipping, spraying or producing dry resist coatings by vacuum deposition, plasma deposition or adsorption, eventually followed by dry development (in situ radiation deposition) [1], [2]. Furthermore, the shadow mask technique can be used to deposit patterns on wafers with deep etch holes. Although with these methods patterning of the wafer surface is no problem, it is not possible to create bridges across the etch holes. Another planarization technique is filling the holes with an organic material, e.g., a polymer, eventually followed by a heating step. The flatness of the structures across the holes will then be determined by the shape of the planarized filling material, which can be a serious restriction in the case of very deep etch holes. Finally, an alternative method is to laminate a thin photosensitive foil. After thinning this layer to about $3 \mu \mathrm{m}$

Manuscript received April 5, 1994; revised May 4, 1995. Subject Editor, N. de Rooij.

The authors are with the Mesa Research Institute, University of Twente, 7500 AE Enschede, The Netherlands.

IEEE Log Number 9413440. by a uniform etch back, the depositing and patterning of new layers is possible. This method was applied recently [3].

By means of the (low temperature) sacrificial wafer bonding technique [4], layer deposition, resist spinning, layer patterning combined with realization of bridges, and cantilevers is possible. Because the bond layer and etch back method can be varied [5], it allows a wide application in microelectro mechanical systems that contain deep trenches. The bond step is carried out either with polymers (at $150^{\circ} \mathrm{C}$ ) or by anodic bonding $\left(\right.$ at $\left.450^{\circ} \mathrm{C}\right)$. The advantage compared to applications of silicon fusion bonding [6], [7] is the low bonding temperature, especially when the polymer bonding is applied.

First, the technique using polymer and anodic wafer bonding will be illustrated by realizing metal bridge connections across a groove in silicon with a depth of $100 \mu \mathrm{m}$. Next, the application of the sacrificial wafer bonding technique, using the polymer wafer bond step, is demonstrated in the realization of a strain based membrane pressure sensor with low residual stress and largely reduced package influences [8].

\section{SACRIFICIAL WAFER BONDING}

Basically the technique consist of four steps, see also Fig. 1. First a wafer, covered with a thin stop layer is bonded (step 1) on top of a device with the deep etched holes. After wafer bonding, the top wafer is etched down (step 2) to the (thin) stop layer. As the next step photoresist is spun on this layer. This was not possible for the original bottom wafer that contains the deep etched features. The stop layer can easily be patterned (step 3) in such a way that all etch holes are covered, as shown in Fig. 2. Original layers on the bottom wafer can be patterned [Fig. 2(a)], but also new layers can directly be deposited on the wafer surface [Fig. 2(b)]. As a final step, the coverage of the etch holes is removed (step 4) and the sacrificial bonding step has been completed. In this last step, the bonding wafer as well as the bonding layer is removed completely. The result is, that the original wafer now contains deep etch holes with patterned original layers, patterned new deposited layers, and, eventually, bridges or cantilevers of new deposited materials.

It is possible to combine several functions in one layer. Depending on the bonding and etch back process, the bond layer could serve as a stop layer as well. Besides, the bond layer could be patterned directly, thus requiring bond layer material bridges and cantilevers across the groove.

Note that the strength, lifetime, and bond area of the bonding are of less importance, since the bond is temporary. More important, however, is the etch stop function of the stop layer. 


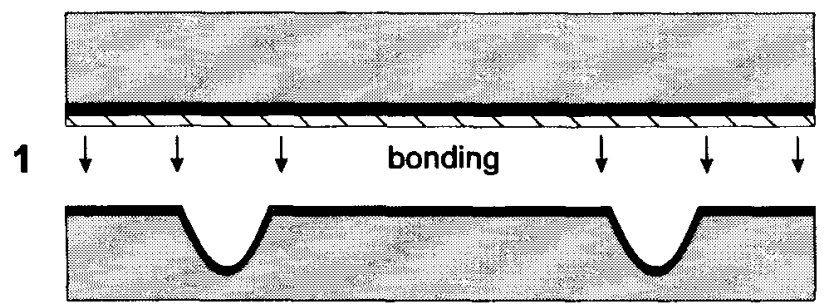

2

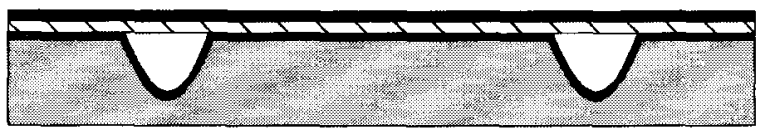

3

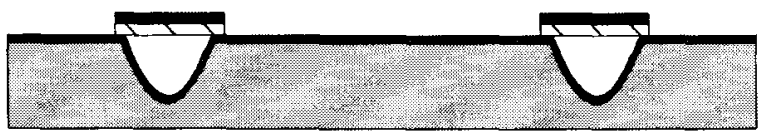

a

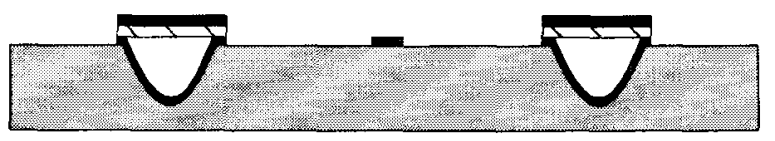

b

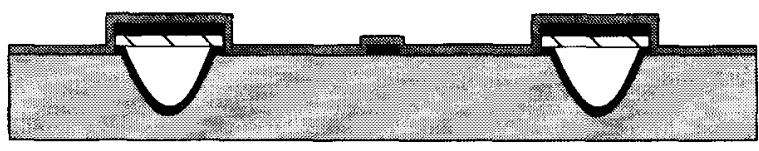

4
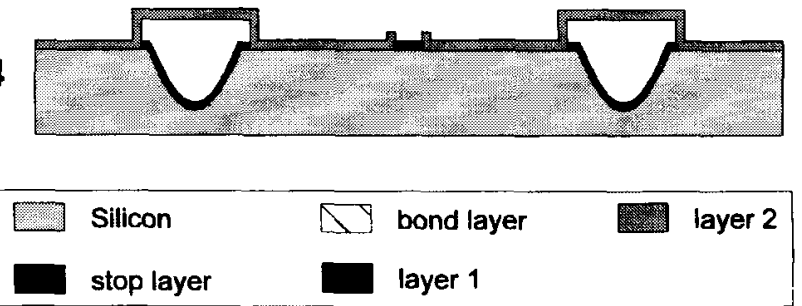

Fig. 1. Main steps of the sacrificial wafer bonding process: 1) on-top bonding of a wafer containing a stop layer, 2) etching of the wafer down to the stop layer, 3) patterning of the stop and bond layer (a: original layers (e.g., layer 1) can be patterned; $b$ : new layers (layer 2) can be deposited and patterned), and 4) removing of the stop and bond layer. (Steps $3 a$ and $b$ are device process steps.)

The technique is demonstrated with two bonding processes and etch back methods. First, the combination of polymer bonding followed by dry etching is applied. Another successful combination is anodic bonding of silicon wafers with a thin layer of sputtered borosilicate glass, followed by an etch back in $\mathrm{KOH}$.

\section{POLYMER BONDING FOLlowed By DRY ETCHING}

The combination of polymer bonding followed by dry etching is discussed. The best results were obtained with the negative photoresist-type 3IC (Olin Ciba Geigy) as bonding layer, applied with a prebake and a postbake step at $150^{\circ} \mathrm{C}$ in a nitrogen environment. The etch back step was carried out in a

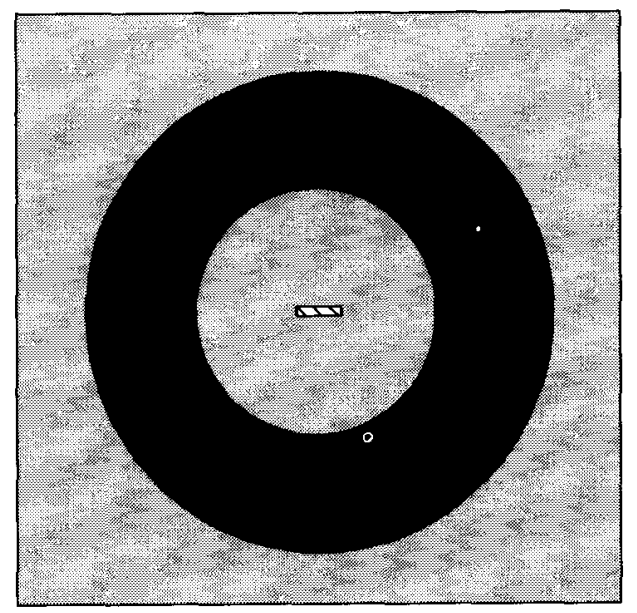

(a)

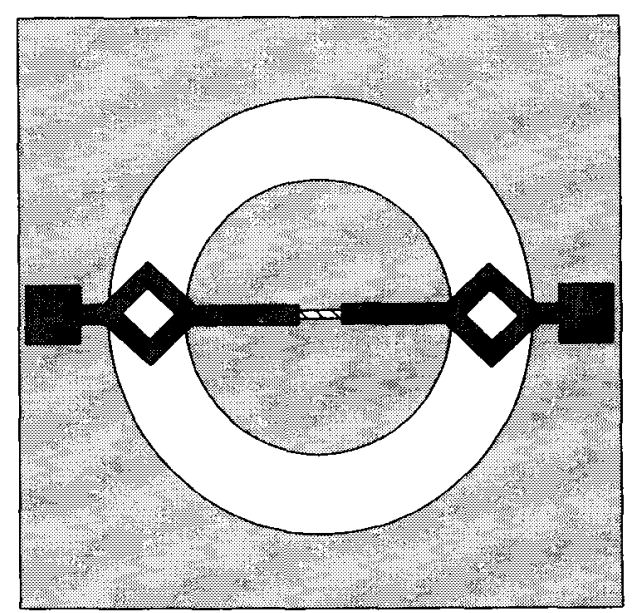

(b)

Fig. 2. Top view of a device after (a) step $3 a$ and (b) step 4 of the sacrificial wafer bonding process.

sulphur-hexafluoride:nitrogen $\left(\mathrm{SF}_{6}: \mathrm{N}_{2}\right)$ plasma in the reactive ion etch mode. Aluminum acted as etch stop layer material.

\section{A. Polymer Bonding}

Before application in the sacrificial wafer bonding method, the polymer bonding of two flat silicon wafers was studied. The absence of the aluminum stop layer offers the possibility to observe the bond layer by infrared imaging.

In [9] and [10], a stamp method was used to apply the polymer bonding layer on areas of $1 \mathrm{~cm}^{2}$. This method could not be used for larger areas, because of destruction of the polymer layer. In this research, a full wafer bonding procedure with spun negative resist 3IC (OCG) is developed. The procedure consists of the following steps:

1) spinning the resist on one wafer $(20 \mathrm{sec}$. at $2000 \mathrm{rpm}$ for 3" wafers; layer thickness $1.4 \mu \mathrm{m}$ ),

2) prebake of $140 \mathrm{~min}$. at $150^{\circ} \mathrm{C}$ in a nitrogen environment,

3 ) contacting of the two wafers in a bonding tool, and

4) postbake of $90 \mathrm{~min}$. at $150^{\circ} \mathrm{C}$ in a nitrogen environment.

Without the prebake step, the evaporation of solvent in the photoresist during the heat treatment after contacting became a 
major problem. This resulted in strongly inhomogeneous bond layers, containing many small nonbonded areas. Gassing out the solvent by prebaking in air leads to hardening of the top layer, due to oxidation of the resist. The bond layer looses its sticking quality in that case. In order to overcome this problem, a prebake in a nitrogen environment was carried out directly after spinning the resist on the (flat) top wafer. Then the solvents can evaporate without oxidation of the polymer layer.

The contacting of the two wafers in a bonding tool took place at room temperature, followed by a postbake step of $90 \mathrm{~min}$. at $150^{\circ} \mathrm{C}$ in the same nitrogen oven as the prebake step. Note that the actual bond step takes place during the higher temperature postbake step, rather than during contact at room temperature. Without the postbake step the sticking quality, and therefore the bond strength, is very poor. The heat treatment resulted in a homogeneous bond layer with sufficient strength for application in the sacrificial wafer bond method. The yield mainly depends on the fact if air is trapped between the two wafers during the wafer contact step in the bonding tool. With the present available (commercial) bonding tools, trapped air bubbles can easily be avoided.

Fig. 3 shows an example of two bare silicon wafers bonded with negative resist. An infrared image of the bonding layer and a photograph of the split wafers are shown. The wafers broke apart in the interior of the photoresist layer, which indicates a large bond strength.

\section{B. Reactive Ion Etching}

Reactive ion etching was used as etch back method since it has the advantage of a large etch rate $(>1.5 \mu \mathrm{m} / \mathrm{min}$.) combined with an almost perfect etch stop on metal. A flat wafer with evaporated aluminum and spun negative resist was polymer-bonded on top of a second wafer that contains deep etched grooves. The top wafer was etched down to the aluminum (see also steps 1 and 2 of Fig. 1). A $0.5-\mu$ m-thick aluminum layer was sufficient to serve as the etch stop layer. The etching was done in a 50:10 sccm $\mathrm{SF}_{6}: \mathrm{N}_{2}$ plasma, at 20 $\mathrm{Pa}$ and $25^{\circ} \mathrm{C}$, in a parallel plate electrode configuration of the type Plasmafab 340. First the (lower) electrode was powered for about $\frac{3}{4}$ hours with $0.83 \mathrm{~W} / \mathrm{cm}^{2}$, until the aluminum stop layer was reached at the outer radius. Then, the process was continued at a reduced power of $0.42 \mathrm{~W} / \mathrm{cm}^{2}$, until the whole top wafer was etched away. The limit of the power (and the belonging etch rate) is the occurring temperature [11]. If the temperature increases too much, the polymer and metal layer can degenerate. This is the reason for performing the powerreduction as soon as the aluminum layer has been reached at the outer radius of the wafer. Wafers with a thickness of 280 $\mu \mathrm{m}$ were removed in circa $2 \frac{1}{2} \mathrm{hrs}$.

The radial nonuniformity of the etch process is caused by the "loading effect" [12], a radius-dependent electrical field, and an inhomogeneous gas flow pattern. The loading effect is characterized by a decrease in etch rate as the quantity of material to be etched is increased, for a given set of etching conditions. In this particular case, the etch process is locally limited by the supply of fresh radicals. It causes a much larger

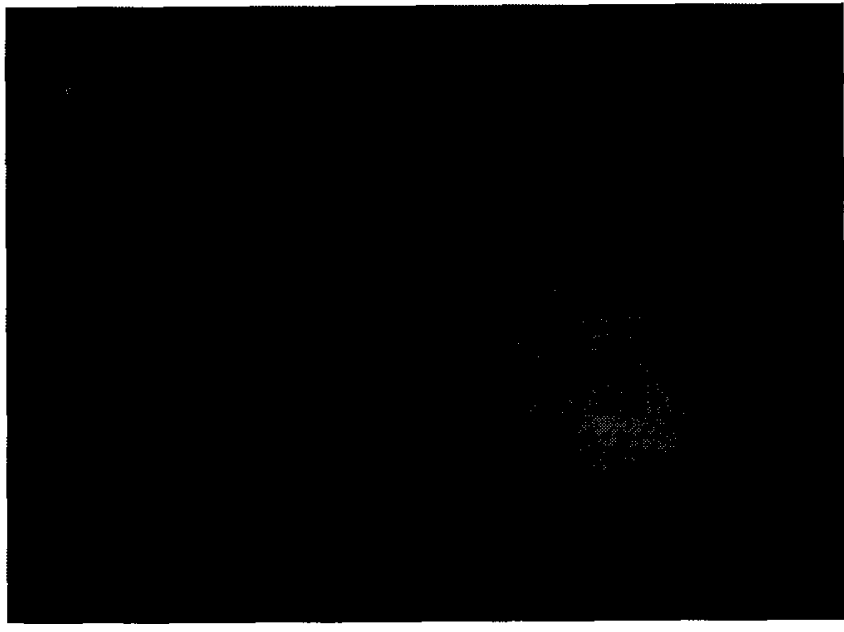

(a)

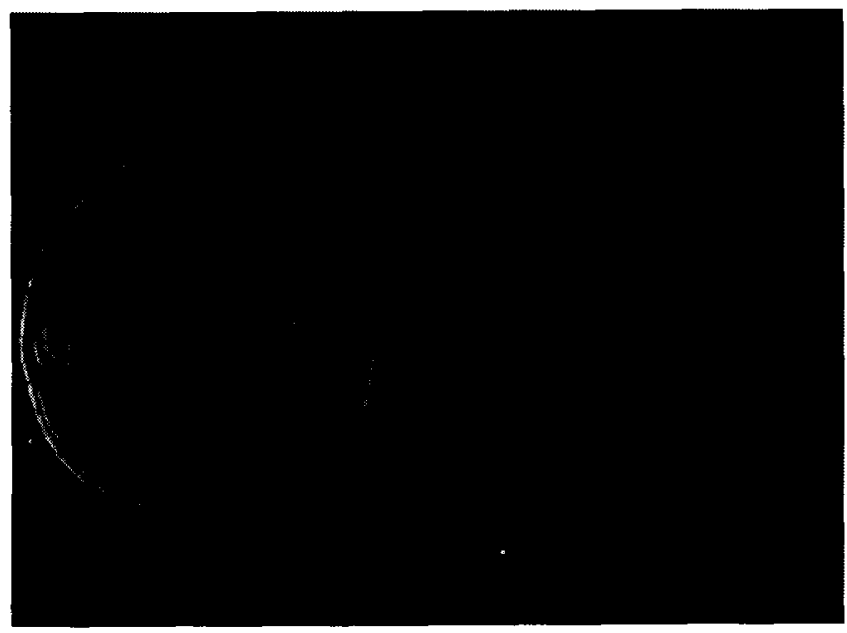

(b)

Fig. 3. (a) Infrared image of a polymer bond and (b) photograph of the two split wafers.

rate at outer radius of the wafer compared to the center etch rate.

The coverage layer of $0.5-\mu \mathrm{m}$-thick aluminum across grooves with a width of $150 \mu \mathrm{m}$ showed a little downwards bending. The center deflection was about $2.2 \mu \mathrm{m}$ and was due to residual stresses in the layer or plastic deformations resulting from a temperature increase during the dry etch back. For the applications in this research, these deformations were not relevant.

\section{Fabrication of Bridges}

The sacrificial wafer bonding technique, using the negative resist as bond layer, is demonstrated by realizing aluminum bridges across deep grooves in a silicon wafer. After bonding and etch back (steps 1 and 2) the aluminum etch stop layer is directly patterned in such a way that aluminum bridges remain (see also Fig. 4). The noncovered negative resist is stripped afterwards in an oxygen plasma (step 3). In this case, aluminum bridges with a resist foundation are realized, becauset there was no new deposition of aluminum. Fig. 5 


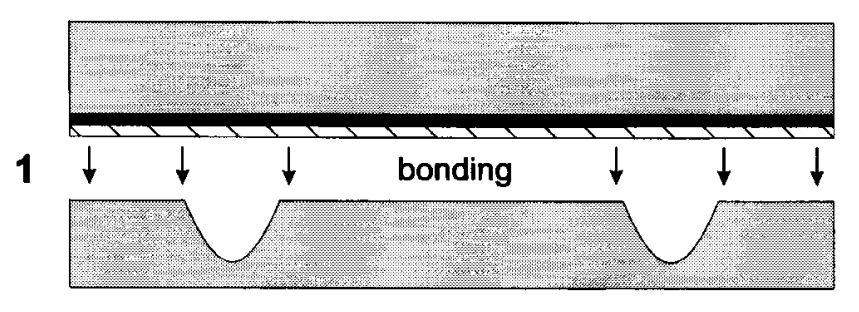

2

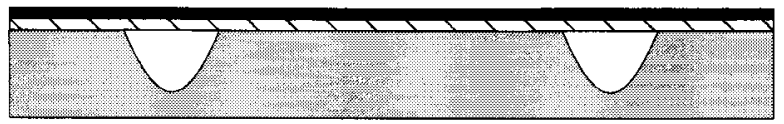

3

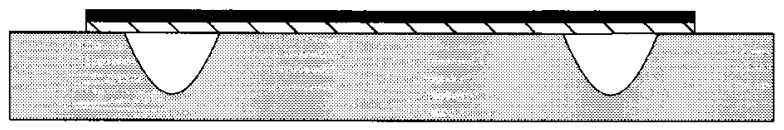

Silicon

$\triangle$ neg. resist

Aluminum

Fig. 4. Process steps for the realization of aluminum bridges across deep silicon grooves by the sacrificial wafer bonding process using polymer bonding and dry etch back: 1) on-top bonding of a wafer containing a stop layer, 2) etching of the wafer down to the stop layer, and 3) patterning of the stop and bond layer.

shows the metal bridges across silicon grooves, fabricated with the sacrificial polymer bonding method. The grooves have a depth of $100 \mu \mathrm{m}$.

\section{ANODIC BONDING FOLLOWED BY KOH ETCHING}

Another successful combination is anodic bonding of silicon wafers with a thin layer of R.F.-sputtered glass, followed by etch back in a $\mathrm{KOH}$-solution. The bonding step took place at a temperature of $450^{\circ} \mathrm{C}$. This approach has the advantage of combining the bonding and etch stop function in one layer. Recently, it was shown that it is possible to use very thin sputtered layers (thickness down to $20 \mathrm{~nm}$ possible), acquiring a good bonding as well as a selective etch stop in $\mathrm{KOH}$ [13].

\section{A. Anodic Bonding}

Borosilicate glass films were sputtered with a Schott 8330 glass target in a Nordiko 2000 system. The sputter density was $1 \mathrm{~Pa}$ and the target R.F.-power density $2.7 \mathrm{~W} / \mathrm{cm}^{2}$. The layers applied in this research were sputtered in $100 \%$ Ar with a thickness of $1.4 \mu \mathrm{m}$ and no anneal step was done. However, an important reduction of compressive stress from $130 \mathrm{MPa}$ to $5 \mathrm{MPa}$ is achieved after an anneal step of $3.5 \mathrm{hrs}$ at $550^{\circ} \mathrm{C}$ in nitrogen ambient [13].

The bonding setup was equipped with an infrared camera, which made in-situ infrared inspection possible. For the 1.4$\mu \mathrm{m}$-thick glass layer, a voltage of $15 \mathrm{~V}$ was needed to start the bonding process. A voltage of $1 \mathrm{~V}$ is sufficient to bond silicon wafers successfully with glass layers of a thickness of $100 \mathrm{~nm}$ or less.

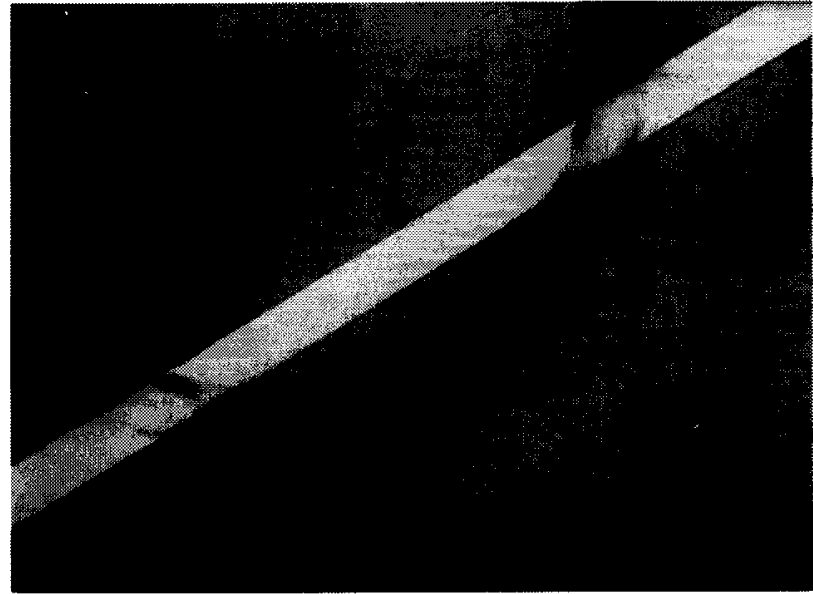

(a)

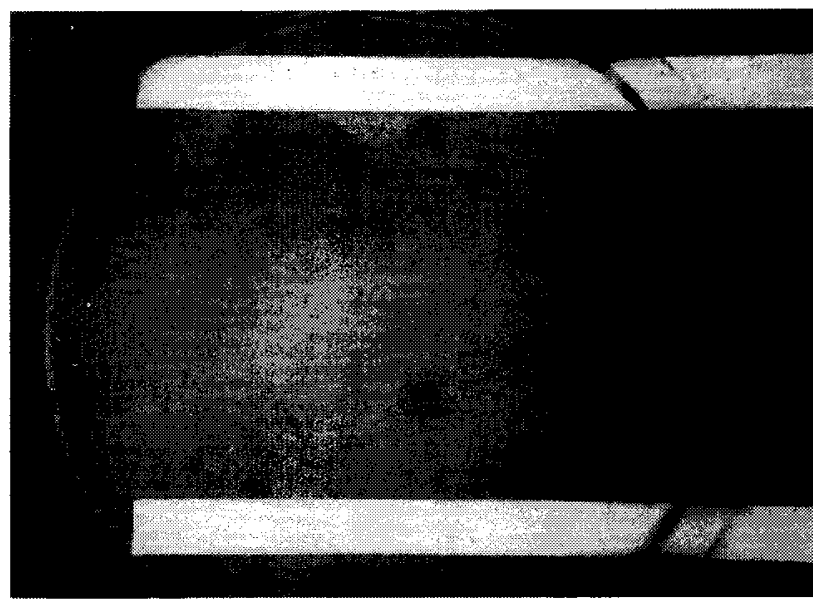

(b)

Fig. 5. (a) Aluminum bridges and (b) cantilevers across deep silicon grooves, realized by the sacrificial wafer bonding process, using polymer bonding and dry etch back.

\section{B. KOH Etch Back}

The etch back was done in a $25 \mathrm{wt} \% \mathrm{KOH}$ solution at $78^{\circ} \mathrm{C}$. The etch rate of the glass layer in this solution is about 260 $\mathrm{nm} / \mathrm{hr}$. The selectivity of silicon to sputtered borosilicate glass amounts 1:200, which implies that also very thin layers can be applied for the sacrificial wafer bonding method.

Also, with this method the film covering the groove showed a bending downwards. The center deflection was about 1.3 $\mu \mathrm{m}$ for a groove width of $125 \mu \mathrm{m}$ and is due to compressive stresses in the glass layer.

\section{Fabrication of Bridges}

The sacrificial wafer bonding technique, using anodic bonding, is demonstrated as well by realizing aluminum bridges across deep grooves in a silicon wafer. After bonding and etch back (steps 1 and 2) an aluminum layer with thickness $0.5 \mu \mathrm{m}$ was evaporated. This layer was patterned in such a way that aluminum bridges remain (step 3). As a consequence, the aluminum bridges are realized with a glass-layer foundation, similar to the bridges realized by the polymer bond method 


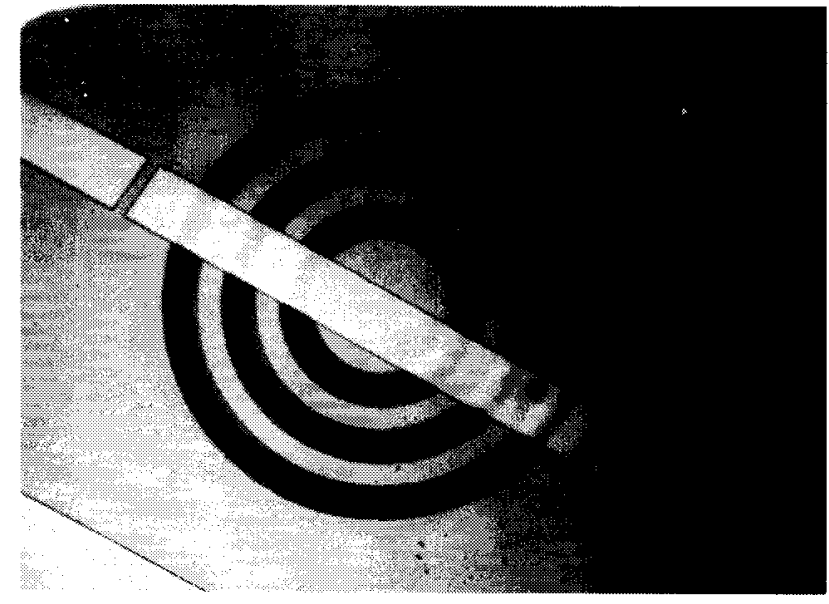

(a)

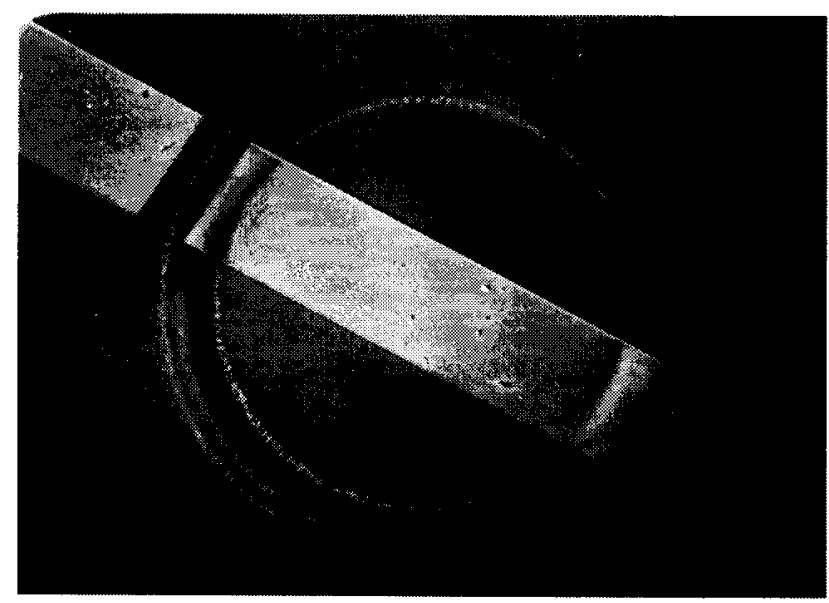

(b)

Fig. 6. (a) Metal bridges and (b) cantilever across deep silicon grooves, realized using the sacrificial anodic wafer bonding process.

(see Fig. 4). A difference to the last method is that the aluminum is evaporated after the etch back. Note that the aluminum now simultaneously serves as structural material and as mask material for etching the underlying glass layer.

The etching of the glass layer was done in a two-step process. First, the layer was etched down to about $100 \mathrm{~nm}$ by reactive ion etching with a $\mathrm{SF}_{6}$-plasma. At that thickness the etch-rate was largely decreasing, possibly due to a large $\mathrm{Na}^{+}$-ion density. The final $100 \mathrm{~nm}$ were etched with a 4:1:2 $\mathrm{NH}_{4} \mathrm{~F}: \mathrm{HF}$ :Glycerol solution, without damage of the aluminum layer. Fig. 6 shows examples of remaining metal bridges and cantilevers across silicon grooves, fabricated with this method. The grooves again have a depth of $100 \mu \mathrm{m}$.

\section{Discussion}

The two examples of the sacrificial wafer bonding method presented illustrate that the technique is a powerful tool in the design and realization of microelectro mechanical systems. Particularly attractive are the wide range of applicable bond and stop layers and etch back methods and the possibility of combining several functions in one layer. The same layer can
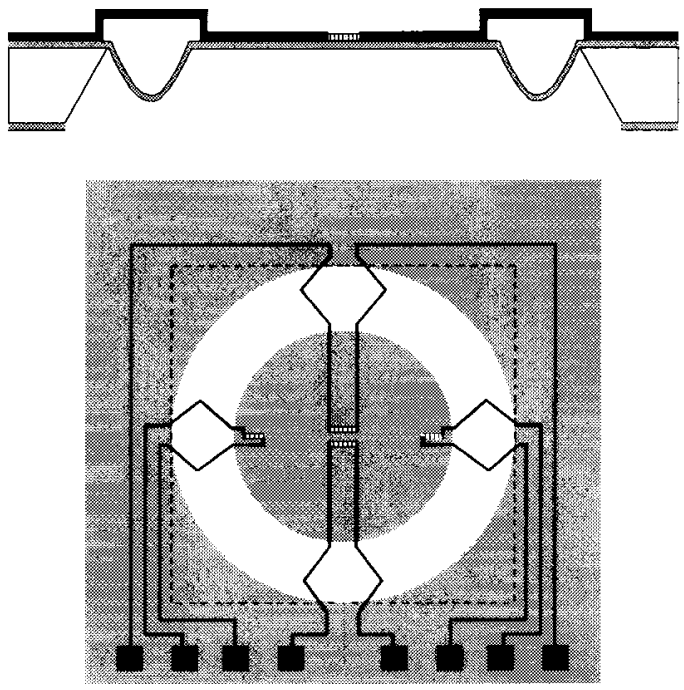

Aluminum

Poly-Si

Fig. 7. Top view and cross-section of the membrane pressure sensor, with a deep corrugation. The patterning of the polysilicon strain gauges and the realization of aluminum contact bridges was done with the sacrificial wafer bonding technique.

serve as an etch stop, bond interface, mask or even as structure material. In the extremity, only one layer suffices to realize bridges across deep-etched features.

After the etch back of the top wafer, the system fabrication process can be continued without any constraint except the limitations brought in by the applied materials itself. This flexibility opens many possibilities for flat layer deposition, resist spinning, and layer patterning, including the realization of bridges and cantilevers, all after a very deep etching step. A different application is to create a shadow mask, after the etch back, to pattern the bottom of a deep etch hole.

The demonstrated methods, using a polymer or sputtered glass as bond layer respectively, have various advantages. On the one hand, the polymer bonding is attractive because of its simple and fast technology and the very low process temperature $\left(150^{\circ} \mathrm{C}\right)$. On the other hand, the succeeding process steps are limited by the maximal tolerable temperature of the negative resist, i.e. about $300^{\circ} \mathrm{C}$. For anodic bonding the bond temperature is higher $\left(450^{\circ} \mathrm{C}\right)$, but there is no stringent temperature limitation for succeeding steps. The serious constraint in this case is the presence of $\mathrm{Na}^{+}$-ions; these can change the electric properties of other components.

In general, the sacrificial wafer bonding method is a rather complex technology and should be avoided when simpler techniques, as mentioned in the introduction, can be applied. However, in cases where planarization of wafers containing deep trenches is required for additional lithographic steps, and/or to fabricate thin, flat, and precise dimensioned bridges across these trenches, it is proved to be a useful technique. Future solutions toward a simplified technology might be found in se application of thin dry multilayer foils. One of the layers can function as the etch stop layer, while the silicon wafer etch back is replaced by a (short) etch back of the thin foil. 


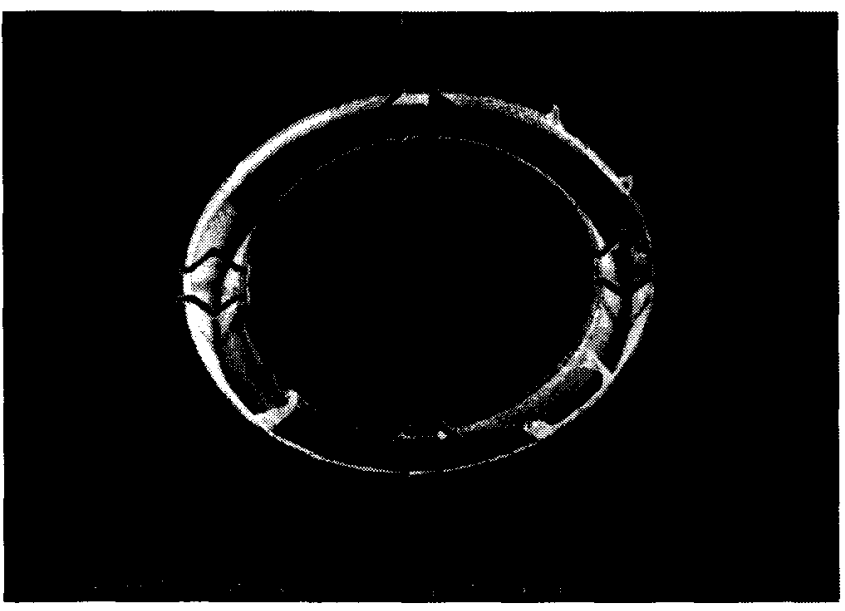

(a)

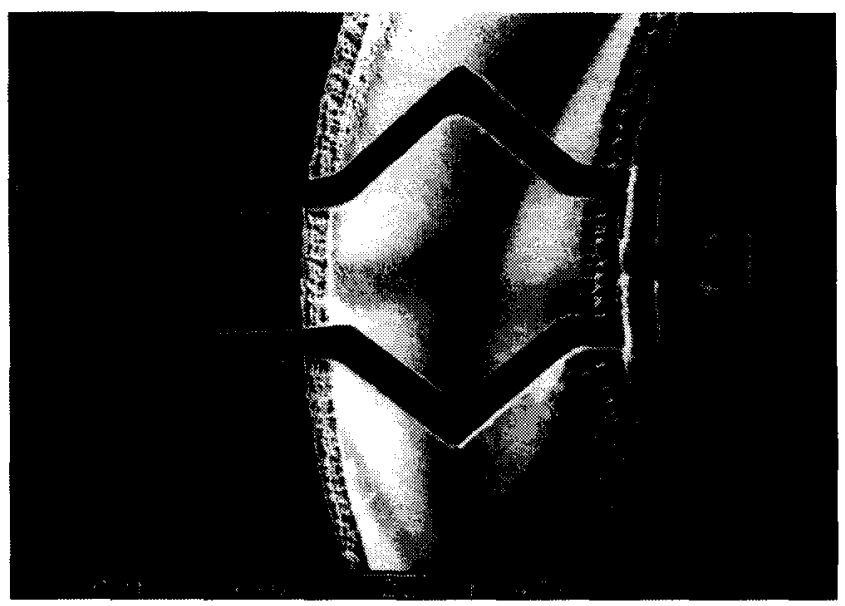

(b)

Fig. 8. Top view of a membrane pressure sensor with aluminum bridges across a deep corrugation to provide electrical contact. (a) Overview with four strain gauges to be applied in a Wheatstone bridge configuration. (b) The bridges are $\mathrm{V}$-shaped to decrease their mechanical influence on the membrane deflections [15].

In the experiments discussed so far, the aluminum bridges were fabricated with a bond layer base. Next, an application will be presented with one of the original bottom layers as direct foundation for aluminum bridges. In the final process step, the bond layer is removed completely so the whole sacrificial wafer bonding step has been carried out.

\section{APPLiCATION}

The polymer bonding technique, in combination with the dry etch back, is applied to fabricate a membrane pressure-sensor with a deep corrugation. The corrugation is added to reduce package stresses and to obtain a residual stress relief in the inner circular membrane without loosing pressure sensitivity [8]. The sacrificial wafer bonding facilitates as well patterning of polysilicon strain gauges on a silicon nitride membrane as the fabrication of metal bridge connections across the deep thin silicon nitride corrugation.

A schematic outline of the fabricated device is shown in Fig. 7. It concerns a square silicon nitride membrane (thickness of $1 \mu \mathrm{m}$ ), containing a 100- $\mu \mathrm{m}$-deep circular corrugation. The corrugations were shaped by first etching deep grooves in silicon by reactive ion etching, followed by a low pressure chemical vapor deposition of silicon nitride [14]. On top of this layer, polysilicon was grown and doped, followed by a deposition of silicon oxide as a temporary protection. So, there are three original layers of the type of layer 1 in Fig. 1. At this stage, the polymer sacrificial wafer bonding technique was applied, and after the planarization the polysilicon strain gauges were patterned. A new aluminum layer was evaporated directly on the nitride and patterned to create bridge-connections between strain gauges inside the corrugation and bond pads outside the corrugation. Finally, the complete bond layer is removed. Fig. 8 shows SEM photographs of the top view of the first realized samples. The characterization and testing is discussed elsewhere [15].

\section{CONCLUSION}

A new flexible technique at low temperature for planarization after a very deep etching step is demonstrated. With this technique not only resist spinning and layer patterning becomes possible, but also the fabrication of bridges and cantilevers across deep grooves or holes. Because of the wide range of possibilities and combinations, the sacrificial wafer bonding technique is very suited for application in micro electro mechanical systems. Results of polymer bonding followed by dry etching and anodic bonding combined with $\mathrm{KOH}$ etching were presented. The polymer bond method was applied in a strain-based membrane pressure sensor to pattern the strain gauges and to provide electrical connections across a deep corrugation in a thin silicon nitride membrane by metal bridges.

\section{ACKNOWLEDGMENT}

The authors gratefully acknowledge the contributions of $\mathbf{H}$. Jansen concerning the optimization of the polymer bonding process. These investigations in the programme of the Foundation for Fundamental Research on Matter (FOM) have been supported by the Netherlands Technology Foundation (STW).

\section{REFERENCES}

[1] S. Morita and S. Hattori, Plasma Deposition, Treatment, and Etching of Polymers, R. d'Agostino, Ed. Academic, San Diego, 1990, pp. 424-443.

[2] W. M. Moreau, Semiconductor Lithography, Principles, Practices, and Materials. NY: Plenum, 1988.

[3] V. L. Spiering, J. W. Berenschot, and M. Elwenspoek, "Planarization and fabrication of bridges across deep grooves or holes in silicon using a dry film photoresist followed by an etch back," J. Micromech. Microeng., vol. 5 pp. 189-192, 1995.

[4] V. L. Spiering, J. W. Berenschot, M. Elwenspoek, and J. H. J. Fluitman, "Low temperature sacrificial wafer bonding for planarization after very deep etching," in 7th IEEE Workshop on Micro Electro Mechanical Systems (MEMS 94), Oiso, Japan, Jan. 25-28, 1994, pp. 69-74.

[5] Ch. E. Hunt and C. A. Desmond, "Thinning of bonded wafers: Etchstop approaches," in Proc. 1st Int. Symp. Semiconductor Wafer Bonding: Science, Technology, and Applications, Phoenix, AZ, Oct. 13-18, 1991, pp. 165-173.

[6] K. Petersen, P. Barth, J. Poydock, J. Brown, J. Mallon, and J. Bryzek, "Silicon fusion bonding for pressure sensors," in Tech. Dig. IEEE SolidState Sensors Workshop, Hilton Head Island, SC, June 4-7, 1988, pp. 144-147. 
[7] S. Kawahito, Y. Sasaki, M. Ashiki, and T. Nakamura, "Micromachined solenoids for highly sensitive magnetic sensors," in Proc. 6th Int. Conf. Solid-State Sensors and Actuators (Transducers '91), San Francisco, CA, June 24-27, 1991, pp. 1077-1080.

[8] V. L. Spiering, S. Bouwstra, J. F. Burger, and M. Elwenspoek, "Membranes fabricated with a deep single corrugation for package stress reduction and residual stress relief," J. Micromech. Microeng., vol. 3, pp. 243-246, 1993.

[9] R. L. Smith and S. D. Collins, "Micromachined packaging for chemical sensors," IEEE Trans. Electron Dev., vol. 35, pp. 787-792, 1988.

[10] C. den Besten, R. E. G. van Hal, J. Muñoz, and P. Bergveld, "Polymer bonding of micro-machined silicon structures," in Proc. 5th IEEE Workshop on Micro Electro Mechanical Systems (MEMS '92), Travemünde, Germany, Feb. 4-7, 1992, pp. 104-109.

[11] H. V. Jansen, J. G. E. Gardeniers, and J. H. J. Fluitman, "A survey on the reactive ion etching of silicon in microtechnology," in Proc. 6th Workshop on Micromachining, Micromechanics and Microsystems (MME '95), Copenhagen, Denmark, Sept. 3-5, 1995.

[12] C. J. Mogab, "The loading effect in plasma etching," J. Electrochem Soc., 124 , pp. $1262-1268,1977$

[13] J. W. Berenschot, J. G. E. Gardeniers, T. S. J. Lammerink, and M Elwenspoek, New applications of r.f.-sputtered glass films as protection and bonding layers in silicon micromachining, Sensors and Actuators $A, 41-42$, pp. $338-343,1994$.

[14] V. L. Spiering, S. Bouwstra, and J. H. J. Fluitman, "Realization of decoupling zones for package-stress reduction," Sensors and Actuators $A, 37-38$, pp. 800-804, 1993.

[15] V. L. Spiering, "Package stress reduction for micromechanical sensors: application in a pressure sensor," Ph.D. thesis, University of Twente, Enschede, The Netherlands, 1994.

Vincent L. Spiering was born on Aug. 31, 1965, in Den Haag, The Netherlands. He received the M.Sc. degree in applied physics from the University of Twente, Enschede, The Netherlands, in 1989.

In the same year he joined the MESA Research Institute at the University of Twente and worked toward the Ph.D., which he received in 1994, on packaging of micromechanical sensors. This was exchanged with a three-months stay at the Institute of Microtechnology, University of Neuchâtel, Switzerland, where he worked on a Bone Implant Relative Displacement System (BIRDS) for biomedical applications. He is currently involved in several micro analysis system-based projects as a contract researcher at MESA.
J. W. Berenschot was born on December 13, 1967, in Winterswijk, the Netherlands. He received the B.Sc. degree in applied physics from the technical high school of Enschede in 1990.

Since 1992, he has worked in the Micromechanics Group of the MESA Research Institute. He is mainly occupied with cleanroom technology, research on and development of new fabrication techniques, and characterization of devices.

Miko Elwenspoek received the M.Sc. and Ph.D. degrees from the Freie Universität Berlin, Germany, the latter on dynamical properties of liquid metals and alloys.

From 1983 to 1987 he did research on the kinetics of crystal growth at the University of Nijmegen, The Netherlands. Since 1987 he has been an associate professor in charge of the Micromechanics Group of the MESA Research Institute.

Dr. Elwenspoek is a member of the MME (Micro Mechanics Europe) Steering Committee and the JourNal OF MICROELECTROMECHANICAL SYSTEMS Steering Committee.

Jan H. J. Fluitman (M'80) was born on March 23, 1938, in Beverwijk, The Netherlands. He received the M.Sc. and Ph.D. degrees in physics from the University of Amsterdam in 1966 and 1970, respectively, in the field of lowtemperature solid-state physics.

He joined the University of Twente in 1970 . His research interests include magnetic recording, optical waveguide sensors, and micromechanics. Since 1982 he has been a full Professor of transducer science and first Chairman of the Sensors and Actuators Research Unit. Since 1990 he has also been Scientific Director of the MESA Research Institute, which combines microelectronics and microsystems activities.

Dr. Fluitman is a member of the Journal of MICROELECTROMECHANICAL SYSTEMS, the Eurosensors Steering Committee, and the World Micro Systems Technology Association. 